\title{
Effect of smoke-free legislation on the incidence of sudden circulatory arrest in the Netherlands
}

Citation for published version (APA):

de Korte-de Boer, D., Kotz, D., Viechtbauer, W., van Haren, E., Grommen, D., de Munter, M., Coenen, H., Gorgels, A. P. M., \& van Schayck, O. C. P. (2012). Effect of smoke-free legislation on the incidence of sudden circulatory arrest in the Netherlands. Heart, 98(13), 995-999. https://doi.org/10.1136/heartjnl-2012301702

Document status and date:

Published: 01/07/2012

DOI:

10.1136/heartjnl-2012-301702

Document Version:

Publisher's PDF, also known as Version of record

Document license:

Taverne

Please check the document version of this publication:

- A submitted manuscript is the version of the article upon submission and before peer-review. There can be important differences between the submitted version and the official published version of record.

People interested in the research are advised to contact the author for the final version of the publication, or visit the DOI to the publisher's website.

- The final author version and the galley proof are versions of the publication after peer review.

- The final published version features the final layout of the paper including the volume, issue and page numbers.

Link to publication

\footnotetext{
General rights rights.

- You may freely distribute the URL identifying the publication in the public portal. please follow below link for the End User Agreement:

www.umlib.nl/taverne-license

Take down policy

If you believe that this document breaches copyright please contact us at:

repository@maastrichtuniversity.nl

providing details and we will investigate your claim.
}

Copyright and moral rights for the publications made accessible in the public portal are retained by the authors and/or other copyright owners and it is a condition of accessing publications that users recognise and abide by the legal requirements associated with these

- Users may download and print one copy of any publication from the public portal for the purpose of private study or research.

- You may not further distribute the material or use it for any profit-making activity or commercial gain

If the publication is distributed under the terms of Article $25 \mathrm{fa}$ of the Dutch Copyright Act, indicated by the "Taverne" license above, 


\title{
Effect of smoke-free legislation on the incidence of sudden circulatory arrest in the Netherlands
}

\author{
Dianne de Korte-de Boer, ${ }^{1}$ Daniel Kotz, ${ }^{2}$ Wolfgang Viechtbauer, ${ }^{3}$ Emiel van Haren, ${ }^{4}$ \\ Devina Grommen, ${ }^{2}$ Michelle de Munter, ${ }^{2}$ Harry Coenen, ${ }^{5}$ Anton P M Gorgels, ${ }^{4}$ \\ Onno C P van Schayck ${ }^{2}$
}

\begin{abstract}
See Editorial, p 961
1 Department of Epidemiology, CAPHRI School for Public Health and Primary Care, Maastricht University Medical Centre, Maastricht, The Netherlands ${ }^{2}$ Department of General Practice, CAPHRI School for Public Health and Primary Care, Maastricht University Medical Centre, Maastricht, The Netherlands

${ }^{3}$ Department of Psychiatry and Neuropsychology, School for Mental Health and

Neuroscience, Maastricht University Medical Centre, Maastricht, The Netherlands ${ }^{4}$ Department of Cardiology, CAPHRI School for Public Health and Primary Care, Maastricht University Medical Centre, Maastricht, The Netherlands ${ }^{5}$ Emergency Medical Service, Public Health Service South Limburg, Geleen, The Netherlands
\end{abstract}

Correspondence to Dianne de Korte-de Boer, Department of Epidemiology, Maastricht University, PO Box 616, 6200 MD, Maastricht, The Netherlands; dianne.dekorte@ maastrichtuniversity.nl

Accepted 11 April 2012

\section{ABSTRACT}

Objective To investigate whether smoke-free legislation in the Netherlands led to a decreased incidence of outof-hospital sudden circulatory arrest (SCA). Smoke-free legislation was implemented in two phases: a workplace ban in 2004 and an extension of this ban to the hospitality sector on 1 July 2008.

Design Weekly incidence data on SCA were obtained from the ambulance registry of South Limburg, the Netherlands. Three time periods were distinguished: the pre-ban period (1 January 2002-1 January 2004), the first post-ban period (1 January 2004-1 July 2008) and the second post-ban period (1 July 2008-1 May 2010). Trends in absolute SCA incidence were analysed using Poisson regression, adjusted for population size, ambient temperature, air pollution and influenza rates. Results A total of 2305 SCA cases were observed (mean weekly incidence $5.3 \pm 2.3 \mathrm{SD}$ ). The adjusted Poisson regression model showed a small but significant increase in SCA incidence during the pre-ban period $(+0.20 \%$ cases per week, $p=0.044)$. This trend changed significantly after implementation of the first ban (with $-0.24 \%$ cases per week, $p=0.043)$, translating into a $6.8 \%$ (22 cases) reduction in the number of SCA cases after 1 year of smoke-free legislation. No further decrease was seen after the second smoking ban.

Conclusions After introduction of a nationwide workplace smoking ban in 2004, a significant decrease in the incidence of out-of-hospital SCA was seen in South Limburg. Poor enforcement of the 2008 hospitality sector ban may account for the fact that no further decrease in the incidence of SCA was seen at this time.

\section{INTRODUCTION}

Both active and passive smoking are well known to have adverse effects on the cardiovascular system. ${ }^{1-5}$ Even brief exposure to low doses of environmental tobacco smoke (or 'secondhand smoke') may lead to cardiovascular diseases among non-smokers. ${ }^{4} 6$ Some of the adverse effects of active smoking on the cardiovascular system are reversible; after smoking cessation the excess risk of cardiovascular disease among smokers drops on average by $50 \%$ within the first year after stopping and disappears completely within 10 years. ${ }^{1}$ An equally rapid effect is suggested from a decline in exposure to secondhand smoke. ${ }^{7}$

To protect citizens from the harm of secondhand smoke, smoking in public places has been prohibited in many countries. In the Netherlands, smoke-free legislation was implemented in two distinct phases. A general workplace smoking ban came into effect on 1 January 2004. Thereafter, on 1 July 2008, catering, sports and cultural sectors (further referred to as the 'hospitality sector') lost their exemption from the initial ban.

Previous studies from other countries have clearly shown that smoking bans prevent admissions to hospital for acute myocardial infarction (AMI). Reported reductions after implementation of smoke-free legislation range from $2 \%{ }^{8}$ to $40 \%{ }^{9}$ Three meta-analyses demonstrated that the risk reduction increases with follow-up time. ${ }^{10-12}$

No other single cardiovascular event has been studied in relationship to the implementation of smoking bans. It is of interest whether the effect of smoke-free legislation can also be seen in out-ofhospital sudden circulatory arrest (SCA), because the medical and societal impact of this condition is high. SCA is an unexpected, non-traumatic loss of vital signs, such as consciousness, arterial pulse, blood pressure and respiration, without preceding complaints or within $24 \mathrm{~h}$ of the onset of complaints. ${ }^{13}$ Coronary heart disease is the most common cause of SCA, accounting for approximately $80 \%$ of all SCA cases. ${ }^{14}$ Other cardiac causes, such as primary electrical heart diseases and cardiomyopathies only account for a small proportion of SCAs in the overall population. Non-cardiac causes of SCA include trauma, intoxication and ruptured aortic aneurysm. ${ }^{15}$ Most out-of-hospital SCA cases are treated by emergency medical services. SCA affects many people who are in apparently good condition (in many people it is the first manifestation of cardiovascular disease ${ }^{1316}$ ), some of whom are still actively participating in the labour force. With a survival chance of only $9-16 \%,{ }^{17-19}$ SCA has a high societal impact.

This study aims to investigate the effect of the 2004 and 2008 smoking ban in the Netherlands on the incidence of out-of-hospital SCA in South Limburg between 1 January 2002 and 1 May 2010. We hypothesised that the incidence of SCA would decline shortly after introduction of each ban. To the best of our knowledge, this is the first study investigating a smoking ban that was implemented in two separate phases and the first to use SCA as main outcome measure. 


\section{METHODS \\ Study population}

This study was conducted in South Limburg, a region in the Netherlands that encloses an area of $661 \mathrm{~km}^{2}(\sim 255$ square miles) and is served by a single, centrally coordinated emergency medical service provider. During the study period, the population averaged 620537 inhabitants, of whom 443600 (71\%) were aged between 20 and 75 years.

\section{Data collection}

Data on SCA incidence were obtained from the routine emergency medical service registry. Data have been prospectively collected in a standardised way. Every time an ambulance is dispatched, ambulance personnel complete a record containing information on age, gender, cause of injury, situation on arrival and medical care provided. These records are kept in the registry for at least 15 years after the event.

All records of events between 1 January 2002 and 1 May 2010 were manually searched by four different researchers for people who were either found dead or received resuscitation or defibrillation. All cases that explicitly fitted the definition of SCA (unexpected, non-traumatic loss of vital signs without preceding complaints or within $24 \mathrm{~h}$ of the onset of complaints) were considered to be confident cardiac caused SCA cases. We excluded subjects with cardiac symptoms $>24 \mathrm{~h}$ before the event and subjects of unknown age, younger than 20 years or older than 75 years. We also excluded subjects with a circulatory arrest after a traumatic event or intoxication, or in the terminal phase of a chronic disease, in order to exclude non-cardiac caused cases of SCA.

All cases of people found dead without the presence of any of the exclusion criteria were also considered to be SCA cases. The records of the remaining, ambiguous SCA cases were copied, blinded for the date of the event and presented to a cardiologist and a member of the emergency medical service. They discussed these cases in order to reach a consensus as to whether or not these were considered to be genuine, cardiac caused SCA cases.

\section{Statistical analysis}

Poisson regression was used to test whether there was a change in the incidence of SCA after the 2004 and/or 2008 smoking ban. Three time periods were distinguished: the pre-ban period, in which no smoking ban was operative (1 January 2002-1 January 2004; 104 weeks); the first post-ban period, in which workplace smoking ban came into effect (1 January 2004-1 July 2008; 235 weeks) and the second post-ban period, in which the both bans were operative (1 July 2008-1 May 2010; 96 weeks). The slope of the Poisson model was allowed to differ between time periods. We tested whether a change in slope between time periods was significantly different from zero.

The main outcome variable was the weekly number of incident SCA cases. Weeks were defined according to calendar weeks from Monday through Sunday. A log-transformed estimate of the weekly population size of South Limburg between 20 and 75 years of age was included in the model as an offset variable, to take into account the number of people at risk. Weekly population estimates were obtained by linearly interpolating monthly population numbers provided by Statistics Netherlands (CBS).

Additional variables that are known risk factors of SCA were chosen a priori to be included in the model: ambient temperature, ${ }^{20-22}$ airborne particulate matter ${ }^{23-25}$ and influenza rates. ${ }^{26}$ Data on ambient temperature were obtained from the Royal Netherlands Meteorological Institute (KNMI). Ambient temperature was measured at two different locations in the study area. We calculated the weekly mean temperature and the weekly range in temperature. Since there is evidence that there is a time lag between changes in temperature and the onset of cardiovascular disease, the mean ambient temperature in the previous week was also included in the model. Data on airborne particulate matter $\left(\mathrm{PM}_{10}\right)$ were obtained from the provincial government of Limburg and the National Institute for Public Health and the Environment (RIVM). In the study area, $\mathrm{PM}_{10}$ was measured at five different locations (rural and urban sites). We used weekly mean $\mathrm{PM}_{10}$ concentrations. The weekly number of influenza-like illnesses per 10000 inhabitants of the Netherlands was provided by the Netherlands Institute for Health Services Research (NIVEL).

An estimate of the reduction in SCA incidence after 1 year of smoke-free legislation was calculated based on the final Poisson regression model. We calculated the difference between the estimated incidence using the pre-existing trend and the estimated incidence using the changed trend after the smoking ban was implemented.

\section{RESULTS}

A total of 2305 SCA cases were observed, with a mean weekly incidence of $5.3 \pm 2.3 \mathrm{SD}$ cases (range $0-14$ cases a week). The population size in the study region decreased over time from 462508 inhabitants between 20 and 75 years of age in the first week to 435560 in the last week of the study period. Of all observed SCA cases, 1677 (72.8\%) were confident SCA cases that received resuscitation and/or defibrillation, 529 (23.0\%) were subjects found dead, and 99 (4.3\%) were ambiguous SCA cases that were included as genuine SCA cases. Of a total of 202 ambiguous SCA cases, 103 were excluded from the analysis. Table 1 shows the distribution of these numbers over the three time periods. Of the 2305 SCA cases, $66.7 \%$ were male and $25.8 \%$ were female and in $7.5 \%$ of all cases the gender was not registered. The mean age of all observed SCA cases was $59.9 \pm 10.8$ SD years. Gender and age of the SCA cases were equally distributed over the three time periods.

The grey line in figure 1 shows the absolute number of observed SCA cases per week during the whole study period. There was no indication of serial dependence in the incidence of SCA (as examined based on the autocorrelation and partial autocorrelation function of the weekly and monthly counts and based on Ljung-Box tests with an increasing number of lags). Furthermore, decomposition of the series into seasonal, trend/cyclical and error components showed no indication of noteworthy seasonal patterns.

Based on the unadjusted (ie, without the covariates ambient temperature, airborne particulate matter and influenza rates) Poisson model, the estimated weekly SCA incidence was 1.05

Table 1 Distribution of incident out-of-hospital sudden circulatory arrest (SCA) cases over three time periods*

\begin{tabular}{llllr}
\hline & $\begin{array}{l}\text { Pre-ban } \\
\text { 104 weeks }\end{array}$ & $\begin{array}{l}\text { Post-ban 1 } \\
\text { 235 weeks }\end{array}$ & $\begin{array}{l}\text { Post-ban 2 } \\
\text { 96 weeks }\end{array}$ & Total \\
\hline Confident SCA cases & 437 & 883 & 357 & 1677 \\
Subjects found dead & 85 & 320 & 124 & 529 \\
$\begin{array}{l}\text { Ambiguous SCA cases } \\
\quad \text { Included }\end{array}$ & 31 & 48 & 20 & 99 \\
$\quad$ Excluded & 21 & 60 & 22 & 103 \\
\hline
\end{tabular}

*The pre-ban period, in which no smoking ban was operative (1 January 2002-1 January 2004): the first post-ban period, in which the workplace smoking ban came into effect (1 January 2004-1 July 2008) and the second post-ban period, in which both smoking bans were operative (1 July 2008-1 May 2010). 


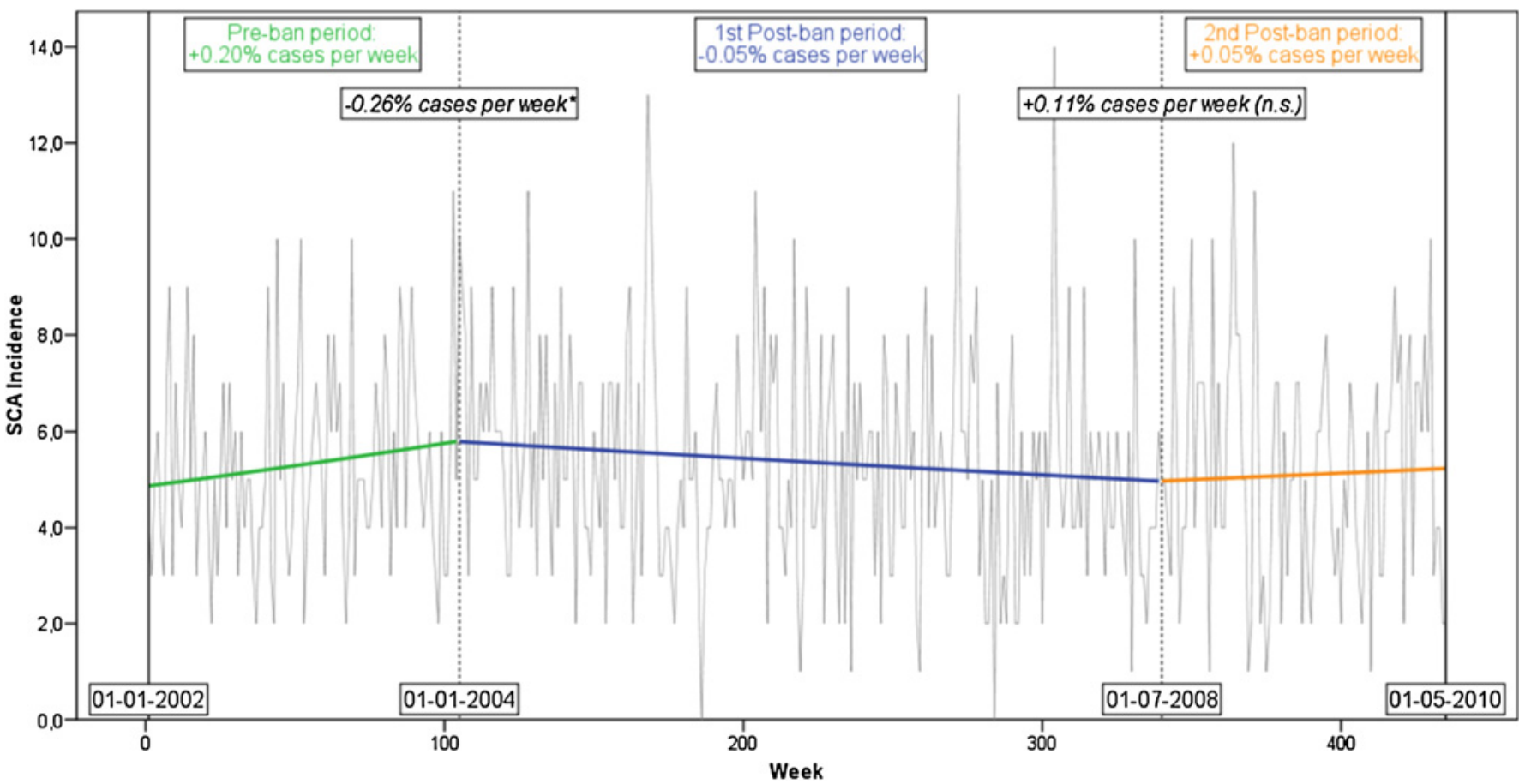

Figure 1 Absolute number of observed cases (grey lines) and trends in the incidence (bold lines) of out-of-hospital sudden circulatory arrest between 1 January 2002 (week 1) and 1 May 2010 (week 435). The vertical dotted lines represent the introduction of the two smoking bans, in week 105 (workplace ban) and week 340 (hospitality sector ban), respectively. The text boxes in the upper part of the figure display the slopes (regular font) and changes in slopes (italic) of the unadjusted Poisson regression model. ${ }^{*}$ Significant change in slope $(\mathrm{p}<0.05)$.

cases per 100000 at the beginning of the pre-ban period. The estimated weekly SCA incidence rose to 1.30 cases per 100000 at the end of this period (ie, an increase of $24 \%$ over 104 weeks, or $+0.20 \%$ cases per week, $\mathrm{p}=0.038$, table 2 ). The introduction of the first ban changed this increasing trend significantly, leading to a decline in the weekly SCA incidence during the first postban period. At the end of this period, the estimated weekly SCA incidence had dropped to 1.14 cases per 100000 (ie, a decrease of $12 \%$ over 235 weeks, or $-0.05 \%$ cases per week, $p=0.098$; change in slope: $-0.26 \%$ cases per week, $p=0.031$, table 2 ). The introduction of the second ban had no further significant influence on this trend; although the estimated weekly SCA incidence had risen to 1.20 cases per 100000 at the end of the second post-ban period (ie, an increase of $5 \%$ over 96 weeks, or $+0.05 \%$ cases per week, $p=0.625$, table 2$)$, the change in the slope was not significant $(+0.11 \%$ cases per week, $p=0.414$, table 2$)$. The trend lines of the unadjusted model are shown in bold lines in figure 1 . The goodness-of-fit test based on the residual deviance suggested that the model fits the data $\left(\chi^{2}=447.17, \mathrm{df}=431\right.$, $p=0.29$ ). Inspection of the (partial) autocorrelation function of the Pearson residuals after fitting the model did not show any serial dependency.

Table 2 Unadjusted Poisson regression model

\begin{tabular}{lrrrl}
\hline Parameter & \multicolumn{1}{l}{ B } & \multicolumn{1}{l}{ Lower } & \multicolumn{1}{l}{ Upper } & Significance \\
\hline (Intercept) & -11.4661 & -11.6218 & -11.3103 & 0.000 \\
Slope pre-ban period & 0.0020 & 0.0001 & 0.0040 & 0.038 \\
Slope post-ban 1 period & -0.0005 & -0.0012 & 0.0001 & 0.098 \\
Slope post-ban 2 period & 0.0005 & -0.0016 & 0.0027 & 0.625 \\
Change in slope ban 1 & $-\mathbf{0 . 0 0 2 6}$ & $-\mathbf{0 . 0 0 4 9}$ & $-\mathbf{0 . 0 0 0 2}$ & $\mathbf{0 . 0 3 1}$ \\
Change in slope ban 2 & $\mathbf{0 . 0 0 1 1}$ & $-\mathbf{0 . 0 0 1 5}$ & $\mathbf{0 . 0 0 3 6}$ & $\mathbf{0 . 4 1 4}$
\end{tabular}

Dependent variable: sudden circulatory arrest incidence; offset variable: population size; covariates: week (pre-ban), week (post-ban 1), week (post-ban 2).
The adjusted Poisson regression model showed almost equal results (table 3): in the pre-ban period the incidence of SCA increased with $+0.20 \%$ cases per week $(p=0.044)$. After introduction of the first smoking ban, this trend changed significantly with $-0.24 \%$ cases per week $(p=0.043)$ to a slope of $-0.04 \%$ cases per week. The extension of the ban in 2008 did not result in a significant change in trend in SCA incidence $(p=0.690)$. None of the covariates had a significant association with the incidence rate ( $p>0.11$ for all covariates). Moreover, there was no evidence of overdispersion in the data (ie, the ratio of the Pearson $\chi^{2}$ statistic to the degrees of freedom was equal to 1.01 and 0.99 for the unadjusted and adjusted models, respectively).

The changing trend after introduction of the workplace smoking ban in January 2004 implies a reduction in SCA cases. Had the ban not been introduced, the estimated SCA incidence

Table 3 Adjusted Poisson regression model

\begin{tabular}{|c|c|c|c|c|}
\hline Parameter & B & Lower & Upper & Significance \\
\hline (Intercept) & -11.4203 & -11.6936 & -11.1470 & 0.000 \\
\hline Slope pre-ban period & 0.0020 & 0.0000 & 0.0039 & 0.044 \\
\hline Slope post-ban 1 period & -0.0004 & -0.0011 & 0.0002 & 0.182 \\
\hline Slope post-ban 2 period & 0.0001 & -0.0021 & 0.0023 & 0.936 \\
\hline Temp mean & 0.0003 & -0.0012 & 0.0018 & 0.704 \\
\hline Temp mean previous week & -0.0012 & -0.0026 & 0.0003 & 0.110 \\
\hline Temp range & -0.0001 & -0.0014 & 0.0012 & 0.860 \\
\hline $\mathrm{PM}_{10}$ mean & 0.0020 & -0.0027 & 0.0066 & 0.412 \\
\hline Influenza rate & 0.001 & -0.013 & 0.015 & 0.901 \\
\hline Change in slope ban 1 & -0.0024 & -0.0048 & 0.0000 & 0.043 \\
\hline Change in slope ban 2 & 0.0005 & -0.0021 & 0.0031 & 0.690 \\
\hline
\end{tabular}

Dependent variable: sudden circulatory arrest incidence; offset variable: population size; covariates: week (pre-ban), week (post-ban 1), week (post-ban 2), mean temperature, mean temperature previous week; temperature range, mean PM10 concentration, influenza rate.

$\mathrm{PM}$, particulate matter. 
in 2004 (week 105 to week 157; ie, the first year of smoke-free legislation) would have been $\sim 322$ cases in total (based on the mean population size of 443600 ). With the influence of the workplace smoking ban taken into account, the estimated SCA incidence was $~ 300$ cases in 2004. This translates into a $6.8 \%$ $((322-300) / 322 \times 100 \%)$ reduction after 1 year of smoke-free legislation.

Three sensitivity analyses were performed to verify whether the resultant regression model was robust. First, we shifted forward the start of the post-ban periods by respectively 1, 2, 3 and 4 weeks, to see if the relatively high incidence rate in the last week of the pre-ban period was of great influence on the regression model. We also shifted the introduction of the bans backwards by 4 weeks, to take into account the situation in which smokers anticipated the coming smoking bans by quitting smoking before the bans came into effect. The resulting incidence trends in all situations were similar to the original analyses. Second, we ran the analysis with the confident SCA cases only. Because of the lower incidence, the resulting slopes did not reach significance, but the direction of the slopes was comparable: a slope of $+0.06 \%$ cases per week in the pre-ban period, a change in slope of $-0.10 \%$ cases per week in the first post-ban period and a change in slope of $+0.01 \%$ cases per week in the second post-ban period. Finally, using a robust (HuberWhite) estimator of the variance-covariance matrix of the parameter estimates yielded no changes in the conclusions.

\section{DISCUSSION}

This study showed that after introduction of a nationwide workplace smoking ban in the Netherlands in 2004, the incidence of out-of-hospital SCA significantly decreased in the region of South Limburg. The extension of the smoking ban to the hospitality sector in 2008 did not lead to a further decrease.

This is the first study to investigate a health effect of two separate smoking bans and the first to use out-of-hospital SCA as the main outcome measure. Therefore, comparisons with other studies are not straightforward. The reduction in SCA incidence after introduction of the workplace smoking ban is in line with reductions found in previous studies on admissions to hospital for AMI, ${ }^{10-12}$ but no other evidence of an isolated effect of a smoking ban in the hospitality sector is available.

The most reasonable explanation for our findings is that, on a population level, the reduction in exposure to secondhand smoke was larger after introduction of the workplace smoking ban than after the smoking ban in the hospitality sector. On average, people spend more time at the workplace than in restaurants or bars. The considerably large effect of the workplace smoking ban in 2004 may have left little room for improvement in 2008, leading to no change at all or a change that was too small to be observed in our study population. A second explanation might be that the chaotic and inconclusive way of enforcing the smoking ban in the hospitality sector, and subsequent poor compliance with the hospitality sector ban in the Netherlands, have resulted in a smaller population health effect. A recently published study by Gonzalez and Glantz gives a good overview of the failing implementation of the hospitality sector smoking ban in the Netherlands. ${ }^{27}$ From the moment of introduction, the hospitality sector smoking ban faced opposition, especially from owners of small bars and cafés, leading to several lawsuits, partial revocation of the ban in $2009^{28}$ and reenforcement of the ban in 2010. While the compliance with the ban was initially high ( $94 \%$ of all hospitality premises were completely smoke-free in the winter of 2008-9), the percentage of non-compliant cafés and discotheques increased significantly from $24 \%$ in $2008-9$ to $50 \%$ in $2010 .^{29}$ In November 2010, the Dutch government agreed on a partial repeal of the smoking ban for small bars and cafés in 2011. Thereafter, 73\% of the exempted small bars and cafés allowed indoor smoking again and $50 \%$ of the cafés that still fell under the ordinance were noncompliant with the smoking ban. ${ }^{30}$

The estimated cumulative risk reduction of $6.8 \%$ after 1 year of the workplace smoking ban is smaller than the $15-36 \%$ reduction on the effect on admissions to hospital for AMI found by previous studies. This is possibly owing to a more complex aetiology of SCA than AMI. While SCA is mostly due to ischaemic heart disease, in approximately $20-30 \%$ of all SCA cases the underlying cause is non-cardiac. In these cases no beneficial effect of reduced exposure to secondhand smoking is expected. Although we made an effort to minimise the number of non-cardiac caused SCA cases in our study by excluding victims of traumatic events and intoxication, the possibility that some non-cardiac caused cases remained in our analysis, might have led to a smaller observed reduction. However, because of the high societal impact of SCA, even a small reduction in incidence is of great benefit for public health and societies. Moreover, the calculation of the absolute reduction after 1 year of smoke-free legislation is merely an illustration of the observed effect. The workplace smoking ban has been effective now for more than 7 years nationwide. When we extrapolate our regional study results to the whole Dutch population $(\sim 16$ million people), the workplace smoking ban prevented at least 784 people having SCA in the first year after the ban came into effect and 16638 people in the whole period between introduction of the first and second smoking ban.

The main limitation of our study is the lack of a control population, which is a common problem in studies on this topic. A geographical control population could only be identified in a neighbouring country where no smoking ban was yet operative; but this was not feasible. Even if it were, it would be hard to obtain adequate comparability, because of cultural, legislative and healthcare differences between countries. Therefore we controlled for a pre-existing trend in SCA incidence in the study region. Results of ecological studies should always be interpreted with caution, because measured or unmeasured factors may be involved that are not accounted for in the analyses.

Another limitation is that we used routinely collected data, lacking individual information on smoking status and exposure to secondhand smoke. This makes it impossible to distinguish between effects of reduction in active and passive smoking. A reduction in active smoking may partly explain the decreased incidence of SCA. From a study on population impact of smokefree legislation in the Netherlands on smoking behaviour, it was concluded that the 2004 workplace smoking ban was followed by more changes in smoking prevalence and smoking cessation attempts than the extension of the smoking ban in 2008. ${ }^{31}$ Furthermore, our study population was relatively small. Replication of our findings in a larger population and based on individual-level data is therefore recommended.

The strengths of this study are that we used a long follow-up period, were able to evaluate two separate phases of smoke-free legislation and evaluated an outcome measure-namely SCA, which has not been previously studied in relation to smoking bans. Also, the main outcome measure of SCA is clearly defined and well registered in the study region. Another strength is that we adjusted for three important predictors of SCA and because of the regional setting of this study we were able to adjust for temperature and airborne particulate matter on a regional level. 
In conclusion, this study adds to the evidence that smoking bans benefit public health by reducing the risk of acute cardiovascular events. Moreover, this study shows that a workplace smoking ban is effective for preventing a condition with a high medical and societal impact. This evidence strengthens the arguments for the introduction and continuation of smoke-free legislation, which is especially important in countries such as the Netherlands where small bars and cafés are exempted from the ban and many other cafés are non-compliant with the ban. Replication of our findings in a larger population and based on individual-level data is recommended.

Acknowledgements The authors thank the Public Health Service South Limburg (GGD Zuid Limburg) for providing access to the emergency medical service registry and MIRO for financing the study.

Contributors DdK-dB monitored and conducted data collection, cleaned and analysed the data and drafted and revised the paper. OvS initiated and designed the study and revised the draft paper. WV wrote the statistical analysis plan, analysed the data and revised the draft paper. DK, HC and AG designed the study and revised the draft paper. EvH designed the study, conducted data collection and revised the draft paper. DG and MdM conducted data collection, cleaned and analysed data and revised the draft paper. All authors had full access to all the data and can take responsibility for its integrity and the accuracy of the data analysis. Data sharing: no additional data available.

Funding This work was supported with an unrestricted educational grant by MIRO-innovation in smoking cessation. MIRO is a collaboration between CAPHRI (Maastricht School for Public Health and Primary Care) and Pfizer Inc.

Competing interests None declared.

Ethics approval Ethics approval was provided by the medical ethical commitee of Maastricht University Medical Centre.

Provenance and peer review Not commissioned; externally peer reviewed.

\section{REFERENCES}

1. McGill HC Jr. The cardiovascular pathology of smoking. Am Heart J 1988;115:250-7.

2. Ambrose JA, Barua RS. The pathophysiology of cigarette smoking and cardiovascular disease: an update. J Am Coll Cardiol 2004;43:1731-7.

3. Glantz SA, Parmley WW. Passive smoking and heart disease. Epidemiology, physiology and biochemistry. Circulation 1991;83:1-12.

4. Barnoya J, Glantz SA. Cardiovascular effects of secondhand smoke: nearly as large as smoking. Circulation 2005;111:2684-98.

5. Raupach T, Schafer K, Konstantinides S, et al. Secondhand smoke as an acute threat for the cardiovascular system: a change in paradigm. Eur Heart J 2006:27:386-92.

6. Law MR, Wald NJ. Environmental tobacco smoke and ischemic heart disease. Prog Cardiovasc Dis 2003;46:31-8.

7. Barnoya J, Glantz SA. Cardiovascular effects of second-hand smoke help explain the benefits of smoke-free legislation on heart disease burden. $J$ Cardiovasc Nurs 2006;21:457-62

8. Sims M, Maxwell R, Bauld L, et al. Short term impact of smoke-free legislation in England: retrospective analysis of hospital admissions for myocardial infarction. BMJ 2010;340:c2161.
9. Sargent RP, Shepard RM, Glantz SA. Reduced incidence of admissions for myocardial infarction associated with public smoking ban: before and after study. BMJ 2004:328:977-80.

10. Lightwood JM, Glantz SA. Declines in acute myocardial infarction after smoke-free laws and individual risk attributable to secondhand smoke. Circulation 2009:120:1373-9.

11. Meyers DG, Neuberger JS, He J. Cardiovascular effect of bans on smoking in public places: a systematic review and meta-analysis. J Am Coll Cardiol 2009:54:1249-55.

12. Mackay DF, Irfan MO, Haw S, et al. Meta-analysis of the effect of comprehensive smoke-free legislation on acute coronary events. Heart 2010;96:1525-30.

13. de Vreede Swagemakers JJ, Gorgels AP, Dubois Arbouw Wl, et al. Out-ofhospital cardiac arrest in the 1990's: a population-based study in the Maastricht area on incidence, characteristics and survival. J Am Coll Cardiol 1997;30:1500-5.

14. Myerburg RJ. Sudden cardiac death: exploring the limits of our knowledge. $J$ Cardiovasc Electrophysiol 2001;12:369-81.

15. Kuisma M, Alaspaa A. Out-of-hospital cardiac arrests of non-cardiac origin Epidemiology and outcome. Eur Heart J 1997;18:1122-8.

16. Gorgels AP, Gijsbers C, de Vreede Swagemakers J, et al. Out-of-hospital cardiac arrest-the relevance of heart failure. The Maastricht Circulatory Arrest Registry. Eur Heart J 2003;24:1204-9.

17. Waalewijn RA, de Vos R, Koster RW. Out-of-hospital cardiac arrests in Amsterdam and its surrounding areas: results from the Amsterdam resuscitation study (ARREST) in 'Utstein' style. Resuscitation 1998;38:157-67.

18. Bottiger BW, Grabner C, Bauer H, et al. Long term outcome after out-of-hospital cardiac arrest with physician staffed emergency medical services: the Utstein style applied to a midsized urban/suburban area. Heart 1999;82:674-9.

19. Mehra R. Global public health problem of sudden cardiac death. J Electrocardiol 2007:40(6 Suppl):S118-22.

20. Goerre S, Egli C, Gerber S, et al. Impact of weather and climate on the incidence of acute coronary syndromes. Int J Cardiol 2007:118:36-40.

21. Mercer JB. Cold-an underrated risk factor for health. Environ Res 2003;92:8-13

22. Bhaskaran K, Hajat $S$, Haines $A$, et al. Effects of ambient temperature on the incidence of myocardial infarction. Heart 2009;95:1760-9.

23. Bhaskaran K, Hajat $S$, Haines $A$, et al. Effects of air pollution on the incidence of myocardial infarction. Heart 2009;95:1746-59.

24. Franchini M, Mannucci PM. Particulate air pollution and cardiovascular risk: shortterm and long-term effects. Semin Thromb Hemost 2009;35:665-70.

25. Pope CA 3rd, Burnett RT, Krewski D, et al. Cardiovascular mortality and exposure to airborne fine particulate matter and cigarette smoke: shape of the exposure-response relationship. Circulation 2009;120:941-8.

26. Warren Gash C, Smeeth L, Hayward AC. Influenza as a trigger for acute myocardia infarction or death from cardiovascular disease: a systematic review. Lancet Infect Dis 2009;9:601-10.

27. Gonzalez $\mathbf{M}$, Glantz SA. Failure of policy regarding smoke-free bars in the Netherlands. Eur J Public Health. Published Online First: 5 December 2011. doi:10.1093/eurpub/ckr173

28. Sheldon T. Legal loophole sees hundreds of Dutch cafes escape smoking ban. BMJ 2009;339:b2824.

29. Intraval/nVWA. [Factsheet Evaluation Compliance Smoke-free Hospitality Sector winter 2010/2011]. Utrecht: Netherlands Food and Consumer Product Safety Authority, 2011.

30. Intraval/nVWA. [Factsheet Evaluation Compliance Smoke-free Hospitality Sector spring 2011]. Utrecht: Netherlands Food and Consumer Product Safety Authority, 2011.

31. Nagelhout GE, Willemsen MC, de Vries H. The population impact of smoke-free workplace and hospitality industry legislation on smoking behaviour. Findings from a national population survey. Addiction 2011:106:816-23. 